\title{
Retraction Note to: Seismic stability of rock slope based on dynamic monitoring and efficacy analysis of psychological intervention in the treatment of depression
}

\section{Shufang Wang ${ }^{1}$}

Published online: 18 November 2021

C Saudi Society for Geosciences 2021

Retraction Note to: Arabian Journal of Geosciences (2021) 14: 1618.

https://doi.org/10.1007/s12517-021-07958-8

The Editor-in-Chief and the Publisher have retracted this article because the content of this article is nonsensical. The peer review process was not carried out in accordance with the Publisher's peer review policy. The author has not responded to correspondence regarding this retraction.

The original article can be found online at https://doi.org/10.1007/ s12517-021-07958-8.

Shufang Wang

wsf0820@163.com

1 Henan Institute of Economics and Trade,

Zhengzhou 450045, Henan, China 